\title{
Physicians' Instructions to Patients Regarding Medications in a Saudi University Hospital
}

\author{
Ashry Gad1, Saud Almousa2*, Mohanned Sharefi², Ali Alshaqrawi1,2, \\ Azzam Alqashami², Meshari Al-Salloom², Abdulaziz Binsaid ${ }^{2}$ \\ ${ }^{1}$ Department of Family and Community Medicine, College of Medicine, King Saud University, Riyadh, \\ Saudi Arabia \\ ${ }^{2}$ College of Medicine, King Saud University, Riyadh, Saudi Arabia \\ Email: "Saud.147@hotmail.com
}

Received 14 September 2015; accepted 8 November 2015; published 11 November 2015

Copyright (C) 2015 by authors and Scientific Research Publishing Inc.

This work is licensed under the Creative Commons Attribution International License (CC BY). http://creativecommons.org/licenses/by/4.0/

(c) (;) Open Access

\begin{abstract}
Objectives: To estimate the proportion of patients who received instructions regarding their medications' functions, methods of administration, dosages, adverse effects, drug-drug interactions, as well as to identify the sources of knowledge concerning medications' instructions. Methods: A cross-sectional study was carried out in King Khalid University Hospital (KKUH) in the out-patient pharmacy in 2013. The data collection method includes personal interview with patients who are randomly selected from adults above 18 years of age. The interview was conducted among patients and any person who attends the consultation. Results: The sample was 274 patients. Patients who received instructions for drugs' functions 208 (75.9\%), method of administration 229 (83.6\%), doses of drugs 220 (80.3\%), drugs' adverse effects 47 (17.1\%), and drug-drug interactions $41(15 \%)$. Sources of medications' instructions were physicians $(73.6 \%)$, pharmacists $(42.3 \%)$, patient information leaflets (PILs) $(40.5 \%)$ and family or friends $(12.8 \%)$. Conclusion: The provided instructions about prescribed medications to patients in KKUH were incomplete that may lead to therapeutic failure.
\end{abstract}

\section{Keywords}

Physicians' Instructions, Prescriptions, Communication, Patients Knowledge

\footnotetext{
"Corresponding author.

How to cite this paper: Gad, A., Almousa, S., Sharefi, M., Alshaqrawi, A., Alqashami, A., Al-Salloom, M. and Binsaid, A. (2015) Physicians' Instructions to Patients Regarding Medications in a Saudi University Hospital. Health, 7, 1441-1447. 


\section{Introduction}

It is an ethical and legal obligation for all healthcare workers to inform their patients about the risks of treatment [1]. However, it has been noticed that patients lack the knowledge about their prescribed medications, which was confirmed by many studies [2] [3]. This may lead to therapeutic failure or some complications due to medications' adverse effects or interactions.

In Iran, only 6\% has received full instructions with regard to their medications' functions, dosage, and duration of medication intake, potential adverse effects, allergies and drug-drug interactions [4]. Another study in California has found that more than $85 \%$ of patients received instructions from their physicians with regard to the following; name, function, method of administration, and duration of intake. Also, the provided instructions relate to medications' adverse effects, what to do if an adverse effect occurs, and interactions were found to be around $60 \%$ [5]. While in India, the method and duration of intake related-instructions showed, more or less, lower percentages compared to California (91\% and $71.2 \%$ respectively) [6].

A study in UK revealed that $66 \%$ of patients do not follow their medications' instructions, while only $24 \%$ were strictly following them. This is due to lack of explanation of the benefits and risks of the medications clearly, while only few patients understood these issues [7]. Moreover, a study revealed that not telling patients the specific time to take their medications may lead to non-compliance [8].

The statistics of ministry of health in Saudi Arabia which took place in 2011 has shown that numbers of Saudi physicians around are only $21 \%$, which may lead to language miscommunication and misunderstanding of the instructions [9]. Moreover, a lack of similar studies has been noticed in Saudi Arabia. Therefore, this research assesses the provided instructions from physicians in King Khalid University hospital (KKUH) regarding their patients medications.

\section{Objectives}

- To estimate the proportion of physicians who provide instructions for their patients regarding the functions, methods of administration, dosage, adverse effects and drug-drug interactions of prescribed medications.

- To identify the sources of medications' instructions that are usually used by patients.

\section{Methodology}

\subsection{Study Design}

The study was quantitative observational cross-sectional.

\subsection{Study Sitting}

It was conducted in King Khalid University Hospital (KKUH) in Riyadh at the out-patient pharmacy in 2013.

\subsection{Sample Size}

The required sample size is estimated to about 310 participants.

\subsection{Sampling Technique}

The sample was randomly selected from males above 18 years who were waiting in the out-patient pharmacy from 7:30 a.m. to 4:00 p.m. The interview was made with the patients themselves or any other person who attended the consultation. We included female patients, but the interview was completed with the husband or son who attended the consultation due to cultural issues and hospital policies. Persons with refill prescriptions were excluded.

\subsection{Data Collection Methods}

Data was collected using a questionnaire which was constructed through extensive literature reviews, and was filled using personal interview. The questionnaire is divided into 3 sections, namely: Personal data (e.g.: age, nationality...etc.), Disease and medication(s) related information (e.g.: functions, adverse effects...etc.), and Source of information related questions (e.g.: the usual source of information). A pilot study was conducted to validate the questionnaire. The study was approved by College of Medicine and King Khalid University Hospital Institutional Ethical Committee. 


\subsection{Data Analysis Plan}

Data were checked for completeness and consistency manually. During collection, SPSS software (version 21) was used for data presentation and analysis. Absolute numbers and percentages were used for data presentation. Chi square test categorical variables associations were used for testing significance at 0.05 .

\section{Results}

A total of 302 patients were interviewed in King Khalid University Hospital at Out-patient Pharmacy to fill the questionnaires. Eight patients refused to be interviewed. Among the interviewed 302 patients 274 were accepted and 28 were excluded due to exclusion criteria (91\%). Most of the interviewed persons (38\%) were middle aged (40 - 59) followed by young aged group (18 - 39) which accounts for $36.9 \%$, and $25.2 \%$ for elderly patients. Saudis constituted the majority (93.1\%) of the participants. $75 \%$ of persons were male patients and $25 \%$ were companies of female patients.

Regarding the sources of medications' instructions (Figure 1), physicians were the most common (76.3\%), followed by pharmacists and PILs (42.3\%, 40.5\% respectively). Family and friends were the least common source (12.8\%).

Figure 2 shows that the information which was received by the physicians was evaluated by the patients as follows: enough (62.4\%), intermediate (26.6\%) not enough (10.9\%). The most common instructions which had



Figure 1. Percentages of common sources of medications' instructions that were utilized by the studied participants in KKUH 2013.

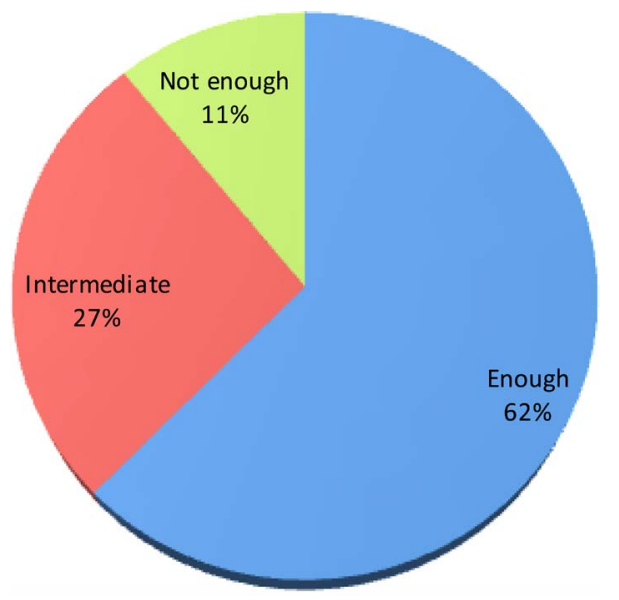

Figure 2. Percentages of overall evaluation about prescribed medications' instructions by the studied participants in KKUH 2013. 
been given to patients were method of administration (83.6\%) followed by duration of intake (82.9\%). On the contrary, drug-drug interactions-related instructions were the most ignored information (15\%) (Table 1).

Table 2 explores the association between the amount of information given by treating physician and respondent perception regarding its satisfaction of their expectation. Significance was found in the first five questions namely: medications' names, functions, methods of administration, dosage and duration $(\mathrm{p} \leq 0.0001)$. Meanwhile, the sixth question, which relates to adverse effects- related instructions showed significance $(\mathrm{p}=0.039)$. In this question, the highest score was found in the category "none of the medications" in relation with the evaluation column "enough".

\section{Discussion}

The current study demonstrates that $70.5 \%$ of physicians give instructions about the name of medications. While a study in USA in 2013 shows 96.3\% [5]. Lower rate in the current study explained that patients may find some difficulties in recalling some of these names. Also, they may not care that much about their medications' names

Table 1. Medications' received instructions among the studied participants in KKUH 2013.

\begin{tabular}{|c|c|c|c|}
\hline Questions & $\begin{array}{l}\text { All } \\
\text { medications }\end{array}$ & $\begin{array}{l}\text { Some } \\
\text { medications }\end{array}$ & None \\
\hline Did the physician inform you about the name(s) of the medication(s) which were prescribed? & $193(70.5)$ & $11(4)$ & $70(25.5)$ \\
\hline Did the physician inform you about the function of each medication? & 208 (75.9) & $26(9.5)$ & $40(14.6)$ \\
\hline $\begin{array}{l}\text { Did the physician provide instructions regarding methods of administration? (E.g. oral, inhaler... } \\
\text { etc.) }\end{array}$ & $229(83.6)$ & $18(6.6)$ & $27(9.9)$ \\
\hline Did the physician provide instructions related to the medication(s) dosage? & $220(80.3)$ & $17(6.2)$ & $37(13.5)$ \\
\hline Did the physician provide instructions related to the duration of each medication intake? & $227(82.9)$ & $17(6.2)$ & $30(10.9)$ \\
\hline Did the physician provide instructions related to the side effects of each medication? & $47(17.1)$ & $12(4.4)$ & $215(78.5)$ \\
\hline $\begin{array}{l}\text { If the answer was "Yes", Did the physician inform you when to stop if these side effects occur? } \\
(\mathrm{n}=47)\end{array}$ & $14(29.8)$ & $0(0)$ & $33(70.2)$ \\
\hline $\begin{array}{l}\text { Did the physician inform you about the risks of certain medication(s) if was/were taken with } \\
\text { other medications? }\end{array}$ & $41(15)$ & $4(1.5)$ & $229(83.5)$ \\
\hline
\end{tabular}

Table 2. The relationship between instructions of drug administration process and overall evaluation of the studied participants in KKUH 2013.

\begin{tabular}{|c|c|c|c|c|c|c|}
\hline \multirow{2}{*}{ Questions } & & \multicolumn{4}{|c|}{ Overall Evaluation number (\%) } & \multirow{2}{*}{ P-value } \\
\hline & & Enough & Intermediate & Not enough & Total & \\
\hline \multirow{3}{*}{$\begin{array}{l}\text { Did the physician inform you } \\
\text { about the function of each medication? }\end{array}$} & All of the medications & $145(84.8)$ & $52(71.2)$ & $11(36.7)$ & 208 (75.9) & \multirow{3}{*}{0.0001} \\
\hline & Some of the medications & $16(9.4)$ & $9(12.3)$ & $1(3.3)$ & $26(9.5)$ & \\
\hline & None & $10(5.8)$ & $12(16.4)$ & $18(60)$ & $40(14.6)$ & \\
\hline \multirow{3}{*}{$\begin{array}{l}\text { Did the physician provide instructions } \\
\text { regarding methods of administration? } \\
\text { (e.g. oral , inhaler... etc) }\end{array}$} & All of the medications & $154(90.1)$ & $59(80.8)$ & $16(53.3)$ & $229(83.6)$ & \multirow{3}{*}{0.0001} \\
\hline & Some of the medications & $11(6.4)$ & $6(8.2)$ & $1(3.3)$ & $18(6.6)$ & \\
\hline & None & $6(3.5)$ & $8(11)$ & $13(43.3)$ & $27(9.9)$ & \\
\hline \multirow{3}{*}{$\begin{array}{l}\text { Did the physician provide instructions } \\
\text { related to the medication(s) dosage? }\end{array}$} & All of the medications & $151(88.3)$ & $57(78.1)$ & $12(40)$ & $220(80.3)$ & \multirow{3}{*}{0.0001} \\
\hline & Some of the medications & $11(6.4)$ & $6(8.2)$ & $0(0)$ & $17(6.2)$ & \\
\hline & None & $9(5.3)$ & $10(13.7)$ & $18(60)$ & 37 (13.5) & \\
\hline \multirow{3}{*}{$\begin{array}{l}\text { Did the physician provide instructions } \\
\text { related to the duration of each } \\
\text { medication intake? }\end{array}$} & All of the medications & $154(90.1)$ & $56(76.7)$ & $17(56.7)$ & $227(82.8)$ & \multirow{3}{*}{$<0.0001$} \\
\hline & Some of the medications & $11(6.4)$ & $6(8.2)$ & $0(0)$ & $17(6.2)$ & \\
\hline & None & $6(3.5)$ & $11(15.1)$ & $13(43.3)$ & 30 (10.9) & \\
\hline \multirow{3}{*}{$\begin{array}{l}\text { Did the physician provide instructions } \\
\text { related to the side effects of each } \\
\text { medication? }\end{array}$} & All of the medications & $37(21.6)$ & $9(12.3)$ & $1(3.3)$ & $47(17.2)$ & \multirow{3}{*}{0.039} \\
\hline & Some of the medications & $9(5.3)$ & $3(4.1)$ & $0(0)$ & $12(4.4)$ & \\
\hline & None & 125 (73.1) & $61(83.6)$ & $29(96.7)$ & $215(78.5)$ & \\
\hline
\end{tabular}


as long as they know the shape of the packets or the pills.

About three quarters of patients in this research have received instructions about functions of all prescribed medications, while the new USA study revealed that $99.1 \%$ were given instructions about medications' functions [5]. In India, on the other hand, the percentage was lower than this study's result $(61.3 \%$ and $75.9 \%$ respectively) [6]. This might be due to low level of awareness in our community compared to USA. Therefore, physicians may find it difficult to explain to patients the benefits of each medication despite being one of their responsibilities.

In regards to the dosage-related instructions, $44 \%$ has received instructions about the issue in Iran [4] compared to the present finding (80.3\%). This variation between the current results and the results in Iran is probably because the study data was restricted to patients attending the outpatient pharmacy, while in Iran samples were collected from community pharmacies. According to the present results, occupation and educational level appears to be statistically significant in relation to dosage instructions ( $\mathrm{p}=0.032, \mathrm{p}=0.046$, respectively).

In USA 93.1\% received instructions on the method of administration [5]. On the contrary, a dramatically low percentage in Iran showed that only 10\% of patients who go to community pharmacies were provided with instructions regarding method of administration [4]. In the current research, it was 83.6\%. In Amsterdam a research showed that around half of inpatients have received instructions regarding the method of administration [10]. This shows that patients in the outpatients' pharmacy have been more informed with regard to the method of administration compared to inpatients' and community pharmacies' patients. Logically, inpatients are less informed on this due to their being under direct supervision of healthcare workers. Regarding community pharmacies, most of the patients there refill their medications, so they are supposed to be already informed by their main source. Gender, nationality and occupation in this study were found to be statistically significant in association with method of administration in the current work ( $p=0.008, p=0.029, p \leq 0.001$, respectively).

Concerning the duration of treatment in the current work, it was shown that $82.9 \%$ of patients were informed. Similarly, a research in California showed that $89.3 \%$ of patients were knowledgeable about this [5]. While a study in Iran showed a very dramatic variation with $9 \%$ only were given instructions from community pharmacies [4]. The reason behind the high percentage of knowledge in the current results may be due to that most of our community patients have chronic diseases, which make them use their medications for life.

With regard to the adverse effects of the instructions, California study revealed that $61 \%$ of patients received instructions from previous appointments [5]. Meanwhile, the current research showed a lower percentage (11.9\%). This low level of patients' knowledge in our community is probably because physicians are afraid that their patients' may not be adherent to their treatment plans if they were informed about their adverse effects. Whereas, some studies showed a higher level of non-compliance among patients who were NOT given clear instructions regarding the risks of their medications, which conflicts our justification about physicians' thoughts [7] [11].

The present study revealed that only 15\% were informed about drug-drug interactions while a study in Switzerland in 2007 showed that about 50\% knew about these interactions [12]. The low percentage of knowledge in current study findings is because the instructions regarding the prescribed medications were only obtained at the point of the interview. Therefore, we would have no information if a patient takes other medications. In contrast, we think that the high percentage in Switzerland is because the sample included people who were taking prescribed medications and over-the-counter (OTC) at the same time.

Regarding the common sources of medications' instructions, majority of the patients in the present study reported physicians as a source of information (76.30\%). A study in Iran showed that physicians were one of the least common sources of medications-related instructions (22\%), whereas family and friends were the most common source [4]. A study by Miina Holappa revealed that physicians were the most common source of information (68\%) [13]. In the current study, the reason for physicians being the most common source of information is that they are considered a very reliable source, and thus are also responsible for patients' health.

Pharmacists and PILs were the next preferred sources in the present study which account for about $40 \%$, although only $11 \%$ of patients in another study by Vivian F. in UK have chosen pharmacists as their primary option [7]. In contrast, pharmacists have a bigger value in Finland as a preferable source of instructions [13] [14].

In Iran, it has been found that there is lack in the use of PILs, which accounts for only $14 \%$ of their patients. The reason could be associated with low educational level [4]. Unlike this study, leaflets were the most common source of information in Finland (74\%) due to the ease of obtaining the information without the need to visit physicians [14]. The possible reason for different percentages between the present study and the other studies 
regarding functions of PILs is thought to be due to the big proportion of elderly people in Saudi Arabia, who are illiterates.

The current study demonstrates that $18 \%$ of patients use internet as an additional source of their medications' instructions. Another published study in Finland also supports the present study by revealing that $20 \%$ of patients preferred internet as their source of information [14]. In comparison to these findings, other conflicting studies by Vivian F. and Forouz Nader in Iran showed dramatic decline in the percentages (6\% and $1 \%$ respectively) regarding the use of internet [4] [7].

A published study in Finland showed that $24 \%$ of patients choose family and friends as a source [14]. Furthermore, the current study revealed a small portion of persons who trust their relatives and friends as a major source of their medications (12\%). On the other hand, In like manner, $41 \%$ of other studies in Iran selected family and friends [4]. From our point of view, family and friends are considered an unreliable source to obtain instructions.

Finally, the last significant value (adverse effects) shows the opposite results by regarding the evaluation column "enough", which reveals the highest percentage among patients who were NOT given any instructions about this issue. This is probably because some patients are over-confident about their treating physicians and this could be as a result of low awareness level of those patients. Another possible reason is that we don't know if the prescribed medications have some sort of adverse effects. Therefore, this study has many limitations ranging from collection of data from various participants, may be patients or companions, particularly for females due to cultural reason.

\section{Conclusion}

The present study concluded that the provided instructions about prescribed medications to patients in KKUH were incomplete. Instructions of adverse effects and drug-drug interactions were frequently missed, and this may lead to therapeutic failure or other complications.

\section{Practice Implications}

Give physicians more time with their patients by increasing the numbers of physicians and clinics or decreasing the allocated number of patients per physician. Also increase patients' awareness about the information needed regarding their medications by media, campaigns, brochures and improving school curriculum.

A couple of hours may be assigned for each physician to answer his/her patients' concerns via email, phone or meeting. A new service may be provided by hospitals which are concerned with patient's needs of information regarding their medications.

\section{Acknowledgements}

The work was supported by College of Medicine Research Center, Deanship of Scientific Research, King Saud University, Kingdom of Saudi Arabia.

\section{References}

[1] Berthelotp, J.M., Glemarec, J., Guillot, P., Chiffoleau, A., Maugars, Y. and Rodat, O. (2003) Informing Patients about Serious Side Effects of Drugs. A 2001 Survey of 341 French Rheumatologists. Joint Bone Spine, 70, 52-57. http://dx.doi.org/10.1016/S1297-319X(02)00011-8

[2] Kerzman, H., Baron-Epelb, O. and Torenc, O. (2005) What Do Discharged Patients Know about Their Medication? Patient Education and Counseling, 56, 276-282. http://dx.doi.org/10.1016/j.pec.2004.02.019

[3] Wolf, M.S., Davis, T.C., Shrank, W., Rapp, D.N., Bass, P.F., Connor, U.M., et al. (2007) To Err Is Human: Patient Misinterpretations of Prescribion Drug Label Instructions. Patient Education and Counseling, 67, 293-300. http://dx.doi.org/10.1016/j.pec.2007.03.024

[4] Nader, F., Mousavizadeh, K. and Ghafourifar, P. (2008) Patient Sources for Drug Information in Iran: A Questionnaire-Based Survey. Pharmacy World and Science, 30, 764-767.

[5] Tarn, D.M., Paterniti, D.A., Orosz, D.K., Tseng, C.H. and Wenger, N.S. (2013) Intervention to Enhance Communication about Newly Prescribed Medications. Annals of Family Medicine, 11, 28-36. http://dx.doi.org/10.1370/afm.1417

[6] Singh, J., Singh, N., Kumar, R., Bhandari, V., Kaur, N. and Dureja, S. (2013) Awareness about Prescribed Drugs 
among Patients Attending Out-Patient Departments. International Journal of Applied and Basic Medical Research, 3 , 48-51. http://dx.doi.org/10.4103/2229-516X.112240

[7] Trewin, V.F. and Veitch, G.B.A. (2003) Patient Sources of Drug Information and Attitudes to Their Provision: A Corticosteroid Model. Pharmacy World and Science, 25, 191-196. http://dx.doi.org/10.1023/A:1025810603241

[8] Davis, T.C., Federman, A.D., Bass, P.F., Jackson, R.H., Middlebrooks, M., Parker, R.M., et al. (2008) Improving Patient Understanding of Prescription Drug Label Instructions. Journal of General Internal Medicine, 24, 57-62.

[9] Ministry of Health. [Online]. 2011. http://www.moh.gov.sa/Ministry/Statistics/book/Documents/1432.rar

[10] Borgsteede, S.D., Karapinar-Carkit, F., Hoffmann, E., Zoer, J. and Bemt, P.M.B. (2011) Information Needs about Medication According to Patients Discharged from a General Hospital. Patient Education and Counseling, 83, 22-28. http://dx.doi.org/10.1016/j.pec.2010.05.020

[11] Tarn, D.M., Heritage, J., Paterniti, D.A., Hays, R.D., Kravitz, R.L. and Wenger, N.S. (2006) Physician Communication When Prescribing New Medications. Archives of Internal Medicine, 166, 1855-1862. http://dx.doi.org/10.1001/archinte.166.17.1855

[12] Indermitte, J., Reber, D., Beutler, M., Bruppacher, R. and Hersberger, K.E. (2007) Prevalence and Patient Awareness of Selected Potential Drug Interactions with Self-Medication. Journal of Clinical Pharmacy and Therapeutics, 32, 149159. http://dx.doi.org/10.1111/j.1365-2710.2007.00809.x

[13] Holappa, M., Ahonen, R., Vainio, K. and Hameen-Anttila, K. (2012) Information Sources Used by Parents to Learn about Medications They Are Giving Their Children. Research in Social and Administrative Pharmacy, 8, 579-584. http://dx.doi.org/10.1016/j.sapharm.2012.01.003

[14] Narhi, U. (2007) Sources of Medicine Information and Their Reliability Evaluated by Medicine Users. Pharmacy World and Science, 29, 688-694. http://dx.doi.org/10.1007/s11096-007-9131-1 